\title{
Depressive features among adult patients receiving antiretroviral therapy for HIV in Rustenburg district, SA
}

\author{
T Bongongo, MB BS, M Med (Fam Med); J Tumbo, MB BCh M Med (Fam Med), MCFP; \\ I Govender, MB BCh, MBA, M Med (Fam Med), AUDOH, FCFP, Dip HIV/AIDS \\ University of Limpopo, Medunsa campus, Pretoria, Gauteng, South Africa
}

Corresponding author: I Govender (indiran.govender@gmail.com)

\begin{abstract}
Background. Globally, it is estimated that depressive features occur in 15 - 36\% of people suffering from chronic diseases and $60 \%$ of people with HIV/AIDS. A high prevalence of mental disorders among HIV-infected individuals has been shown in South Africa and other parts of sub-Saharan Africa. Untreated depression leads to poor adherence to treatment and poor quality of life for patients with chronic diseases.

Methods. Using the Zung self-rating scale, we screened for depressive features among adult patients receiving highly active antiretroviral therapy (HAART) who attended primary healthcare facilities in the Rustenburg district of North West Province in South Africa during December 2009.

Results. Among 117 participants, 81 (69.2 \%) had mild depressive features, 2 (1.7\%) had moderate depressive features, $1(0.9 \%)$ had severe depressive features and $33(28.2 \%)$ did not have depressive features. Depressive features were more common in males (77.1\%) than in females (69.5\%), and were most common in patients taking the combination of efavirenz, lamivudine and stavudine.

Conclusion. Depressive features seem to be common among adult patients receiving HAART and attending primary healthcare facilities in the Rustenburg district.
\end{abstract}

S Afr J Psych 2013;19(2):31-34. DOI:10.7196/SAJP.418

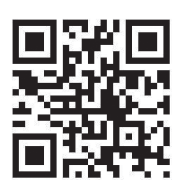

The Diagnostic and Statistical Manual of Mental Disorders (DSM-IV-TR) describes major depressive disorder as being accompanied by clinically significant distress or impairment in social, occupational or other important areas of functioning. ${ }^{[1]}$ Depression is common among patients suffering from chronic diseases such as HIV/AIDS, and can exacerbate these diseases. ${ }^{[2]}$ Depression is also expected to become the second-leading cause of disease burden by the year 2020, after heart disease. ${ }^{[2]}$ Undiagnosed and untreated depression in patients suffering from HIV/AIDS leads to poor adherence to medication and lowers quality of life. A better understanding of the inter-relationships between common mental disorders, especially depression, and HIV/AIDS is important to improving the health of people suffering from these disorders. ${ }^{[3]}$

In South Africa (SA), depression is common among the general population and occurs more frequently in patients suffering with HIV/AIDS. ${ }^{[4-6]}$ SA morbidity data show that mental disorders are the third-highest contributor to the local disease burden, after HIV and other infectious disorders. A high prevalence of mental disorders among HIV-infected individuals has been shown in SA as well as in other parts of sub-Saharan Africa. ${ }^{[6]}$

The prevalence of mental disorders in the adult African rural community of SA is $23.9 \%$, and $4.8 \%$ of these disorders are major depression. ${ }^{[7]}$ The link is partly related to the stress associated with being diagnosed with a highly stigmatised chronic condition, as well as the direct effect of HIV on the central nervous system later in the course of disease. ${ }^{[5]}$
The treatment given for HIV has been associated with high levels of depression, which can be caused by the antiretroviral drug efavirenz. In one study $60 \%$ of people with HIV/AIDS receiving efavirenz had depression. ${ }^{[3]}$ The importance of the link between HIV and mental disorders has been stressed in the South African Stress and Health (SASH) study. ${ }^{[8]}$ However, despite the heavy impact of both HIV and mental disorders, the interactions between them have received little attention in SA and other low- and middle-income countries. ${ }^{\left[{ }^{[9}\right.}$

The 2008 South African National Survey estimated the HIV/AIDS prevalence among adults aged 25 years and older to be $16.9 \%$. HIV prevalence in North West Province in 2008 was estimated at $11.3 \% .{ }^{[10]}$ The HIV Counselling and Testing (HCT) campaign conducted from 2010 to 2012 revealed a HIV prevalence of $17.4 \%$ in the province's general population; ${ }^{[1]}$ therefore, the disease burden of HIV/AIDS is considerable in the region of our study.

In 2009 the Rustenburg district had a population of 433701 and an estimated HIV prevalence of $34 \%$. It has successfully implemented a decentralised approach to the care of these patients, ${ }^{[10]}$ in which comprehensive care, management and treatment of HIV, including the provision of highly active antiretroviral therapy (HAART), are offered at the district's primary healthcare (PHC) facilities (community health centres and PHC clinics). In 2009, 820 HAART patients were down-referred from the referral hospital to $3 \mathrm{PHC}$ facilities accredited to provide HAART.

By 2012, the number of patients in the district had increased to $>15000$ and the number of PHC facilities offering HAART to 21 . With these increasing numbers, we noticed an apparently 
high prevalence of depressive features among patients receiving HAART. As there was no routine screening for depression, many patients were not being treated for it.

Our study sought to establish the prevalence of depressive features among adult patients receiving HAART attending PHC facilities in Rustenburg, with a view to implementing a standard screening programme to identify patients and guide appropriate management.

\section{Methods}

A cross-sectional study was conducted using the Zung self-rating depression scale to screen for depressive features. ${ }^{[12]}$ All adult patients received HAART for $>6$ months who attended the PHC facilities in Rustenburg were included. We sequentially sampled 117 of the eligible 820, as determined using the Epi Info calculator. The sample size was calculated for the purpose of detecting differences in depressive symptoms and estimating for a power of $80 \%$. Consenting adult patients (aged $\geq 18$ years) receiving HAART were included in the study. Patients who were unwilling to participate, unable to communicate in Setswana or English, unable to consent to the study or found to be too ill, were excluded.

The Zung questionnaire was administered by a trained research assistant in either English or Setswana according to the participant's choice. Each questionnaire was assigned a unique number. To ensure anonymity and confidentiality, no personal identifiers of patients were recorded. The data were captured and analysed using SPSS (version 17). Where appropriate, chi-squared and Fisher's exact tests were done for group comparisons to determine statistical significance.

Scores were categorised according to the criteria of the Zung self-rating scale as follows: no depressive features - 0 - 49; mild depressive features - 50 - 59; moderate depressive features 60 - 69; severe depressive features - 70 - 79; and very severe depressive features $-\geq 80$. Descriptive statistical analyses done depicted frequencies, prevalence rates, proportions, mean and median measures of the variables. The severity of depressive features was compared across age, sex, marital status and HAART treatment type.

The Medunsa Research, Ethics and Publications Committee (MREC) approved the study. Permission to conduct the study was obtained from the District Manager of the North West Province Department of Health. Informed consent was obtained from all study participants prior to data collection.

\section{Results}

A total of 117 patients participated in this study. The median age of the respondents was 36 years. There were more females $(70 \%)$ than males $(30 \%)$. The unemployment rate was high $(76.9 \%)$. The majority of the participants (70.1\%) were unmarried. Demographic traits are compiled in Table 1.

\section{Antiretroviral regimen used by the participants (type and frequency)}

More than half of the participants (58.1\%) were receiving lamuvidine, stavudine and efavirenz; $27 \%$ were receiving lamuvidine, stavudine and nevirapine; $5 \%$ were receiving zidovudine, lamuvidine and efavirenz; $4.3 \%$ were receiving zidovudine and lamuvidine. Two participants (1.7\%) were receiving kaletra, stavudine and lamuvidine.

\section{Severity of depressive features}

Of the participants, $69 \%$ had mild depressive features; $28 \%$ had no depressive features, while small proportions of $2 \%$ and $1 \%$ had moderate and severe depressive features respectively. There was no statistical difference between males and females with regard to severity of depressive features $\left(\chi^{2}=2.24\right.$; degrees of freedom $\left.(d f)=3 ; p=0.15\right)$ Data regarding severity are compiled in Tables 2 and 3.

\section{Comparison of age category and severity of depressive features}

There were no significant differences $\left(\chi^{2}=9.27 ; p=0.11\right)$ between age group and severity of depressive features. There were significant statistical differences in severity of depressive features between the married group and participants with any other marital status. $\left(\chi^{2}=63.4 ; d f=9 ; p<0.05\right)$ (Table 4$)$.

\section{Comparison of ARV regimen and severity of depressive features}

Of all patients receiving the combination stavudine, lamuvidine and efavirenz $(n=68)$,

Table 1. Demographic characteristics $(N=117)$

\begin{tabular}{|c|c|}
\hline Categories & $n(\%)$ \\
\hline \multicolumn{2}{|l|}{ Age (years) } \\
\hline $20-29$ & $14(12.0)$ \\
\hline $30-39$ & 49 (41.9) \\
\hline $40-49$ & $38(32.5)$ \\
\hline$\geq 50$ & $16(13.6)$ \\
\hline \multicolumn{2}{|l|}{ Sex } \\
\hline Male & 35 (29.9) \\
\hline Female & $82(70.1)$ \\
\hline \multicolumn{2}{|l|}{ Marital status } \\
\hline Unmarried & $82(70.1)$ \\
\hline Married & $32(27.3)$ \\
\hline Divorced & $1(0.9)$ \\
\hline Widowed & $2(1.7)$ \\
\hline \multicolumn{2}{|l|}{ Employment } \\
\hline Unemployed & $90(76.9)$ \\
\hline Non-professional & $22(18.8)$ \\
\hline Professional & $2(1.7)$ \\
\hline Pensioner & $3(2.6)$ \\
\hline
\end{tabular}

Table 2. Severity of depressive features

\begin{tabular}{ll}
\hline Depressive feature & $\boldsymbol{n}(\%)$ \\
\hline None & $33(28.2)$ \\
Mild & $81(69.2)$ \\
Moderate & $2(1.7)$ \\
Severe & $1(0.9)$ \\
Total & $117(100.0)$
\end{tabular}

Table 3. Severity of depressive features compared by sex

\begin{tabular}{|c|c|c|c|c|}
\hline Sex & $\begin{array}{l}\text { No depressive features } \\
n(\%)\end{array}$ & $\begin{array}{l}\text { Mild depressive features } \\
n(\%)\end{array}$ & $\begin{array}{l}\text { Moderate depressive features } \\
n(\%)\end{array}$ & $\begin{array}{l}\text { Severe depressive features } \\
n(\%)\end{array}$ \\
\hline Female $(n=82)$ & $24(29.3)$ & $58(70.7)$ & $0(0)$ & $0(0)$ \\
\hline Male $(n=35)$ & $6(17.1)$ & $27(77.1)$ & $1(2.9)$ & $1(2.9)$ \\
\hline Total $(N=117)$ & $30(25.4)$ & $85(72.6)$ & $1(0.85)$ & $1(0.85)$ \\
\hline
\end{tabular}


Table 4. Comparison of marital status and severity of depressive features

\begin{tabular}{lllll}
\hline & $\begin{array}{l}\text { No depressive features } \\
\boldsymbol{n}(\%)\end{array}$ & $\begin{array}{l}\text { Mild depressive features } \\
\boldsymbol{n}(\%)\end{array}$ & $\begin{array}{l}\text { Moderate depressive features } \\
\boldsymbol{n}(\%)\end{array}$ & $\begin{array}{l}\text { Severe depressive features } \\
\boldsymbol{n}(\%)\end{array}$ \\
\hline Single $(n=82)$ & $20(24.4)$ & $61(74.4)$ & $1(1.2)$ & $0(0)$ \\
Divorced $(n=1)$ & $0(0)$ & $1(100)$ & $0(0)$ & $0(0)$ \\
Married $(n=32)$ & $12(37.5)$ & $19(59.4)$ & $1(3.1)$ & $0(0)$ \\
Widowed $(n=2)$ & $0(0)$ & $1(50.0)$ & $0(0)$ & $1(50.0)$ \\
Total $(N=117)$ & $32(27.3)$ & $82(70.1)$ & $2(1.7)$ & $1(0.9)$
\end{tabular}

Table 5. Comparison of ARV regimen and severity of depressive features

\begin{tabular}{|c|c|c|c|c|c|}
\hline ARV regimen & $\begin{array}{l}\text { No depressive } \\
\text { features } \\
n\end{array}$ & $\begin{array}{l}\text { Mild depressive } \\
\text { features } \\
n\end{array}$ & $\begin{array}{l}\text { Moderate depressive } \\
\text { features } \\
n\end{array}$ & $\begin{array}{l}\text { Severe depressive } \\
\text { features } \\
n\end{array}$ & $\begin{array}{l}\text { Study participants } \\
\text { on this regimen } \\
\%\end{array}$ \\
\hline stavudine, lamuvidine and nevirapine $(n=30)$ & 6 & 24 & 0 & 0 & 27.4 \\
\hline lamuvidine, zidovudine and nevirapine $(n=10)$ & 2 & 8 & 0 & 0 & 8.5 \\
\hline lamuvidine, stavudine and kaletra $(n=2)$ & 0 & 2 & 0 & 0 & 1.7 \\
\hline Total $(N=117)$ & 30 & 84 & 2 & 1 & 100 \\
\hline
\end{tabular}

72\% were depressed. The Fisher's exact test shows those patients receiving stavudine, lamuvidine and efavirenz had significantly more depressive symptoms than those receiving any other combination of HAART $(p<0.0001)$ (Table 5). Thirty patients were receiving stavudine, lamuvidine and nevirapine. Ten were receiving lamuvidine, zidovudine and efavirenz.

\section{Discussion}

Depressive features are common among adult patients receiving HAART and attending PHC facilities in Rustenburg district. They occur in $71.8 \%$ of the patients, with $69.2 \%$ having mild depressive features, $1.7 \%$ moderate depressive features and $0.9 \%$ severe depressive features.

This study found no relationship between age and depressive features among patients receiving HAART. Harvard Medical School reports that depression can occur at any age, and that individuals may experience depression at different times of their lives for different reasons. ${ }^{[13]}$ Generally, depression is increasing among adolescents. ${ }^{[14,15]}$ However, in a study in another African country, Nigeria, there was no significant association between depression and age. ${ }^{[16]}$ Notably, ageing exposes HIV/AIDS patients to an increased risk of common diseases such as heart disease, cancer, osteoporosis, stroke, dementia and depression. ${ }^{[17,18]}$

The SASH study found the prevalence rate of depressive symptomatology to be almost equal in both sexes, ${ }^{[6]}$ and we found no statistical differences between males and females suffering from depressive features. Although men and women experience depression in different ways, and the gender ratio varies among different countries, many studies report no differences. ${ }^{[19]}$ However, in Africa there are higher rates of depression among men than among women in psychiatric institutions. ${ }^{[20]}$

There were significant statistical correlations between marital status and depression. Although married patients experience longer event-free periods than unmarried patients, the severity of depressive symptoms is similar between married and unmarried patients. ${ }^{[21]} \mathrm{Low}$ social support causes more stress and can accelerate or worsen the progression from HIV to AIDS. ${ }^{[22,23]}$

Both men and women in the first marriages fare better in terms of depressive symptoms compared with those in other marital status categories. ${ }^{[25]}$ The benefits of marriage and its general contribution to well-being are greater for men than women. The rate of depressive features is lower for married than for single or divorced individuals. ${ }^{[26]}$ The SASH study also found that mood disorders were more frequent among separated, widowed and divorced individuals and among people with only an elementary school level of education. ${ }^{[8]}$

In our study the finding was that depressive features were more common among the unemployed $(N=90)$. Depression resulting from unemployment has increased over the years. ${ }^{[27]}$ Major depressive disorder or even milder depressive symptoms are associated with a significant decrease in all quality of life domains and worsen with ageing. ${ }^{[28]}$

The negative impact that depression can create in the community in terms of economic productivity is well described. ${ }^{[4,29]} \mathrm{Zulu}^{[30]}$ describes unemployment linked to depression as the worst killer in Africa,and unemployment itself causes mental and physical hardship. ${ }^{[31]}$

This study's main finding is that most of the respondents with mild depressive features $(69.2 \%)$ were unaware of such symptoms. This is similar to findings by Kartha ${ }^{[32]}$ that while mild depression is common among both women and men, many sufferers are not aware of it. Mild depression can be due to endogenous depression or linked to external factors (exogenous depression), e.g. major worries or family tragedy. ${ }^{[33]}$

Patients receiving HAART and living in rural areas are more vulnerable to depression than those living in urban areas, ${ }^{[34]}$ and the condition can be severe or mild. ${ }^{[35]}$

Patients receiving antiretroviral therapy are usually recieving 3 drugs, and this study's main finding is that the percentage of 
depressive features was higher among participants using the regimen of stavudine, lamivudine and efavirenz (58\%) followed by those who were taking stavudine, lamivudine and nevirapine (24.7\%). Efavirenz may cause severe depression and psychotic-like symptoms; ${ }^{[36]}$ in Cape Town it was found to cause mental disorders. ${ }^{[37]}$

Literature supports the idea that many risk factors can cause depression in adult HIV/AIDS patients. ${ }^{[38]}$ According to Lovegrove, ${ }^{[39]}$ depressive features may be caused by drugs, especially efavirenz, by certain diseases (anaemia or diabetes), and by deficiencies of testosterone, vitamin $\mathrm{B}_{6}$ or vitamin $\mathrm{B}_{12}$. Other risk factors include being female, previous personal or family history of mental illness, alcohol and substance abuse, insufficient social support, and poor adherence to antiretroviral therapy ${ }^{[39]}$

\section{Study limitations}

The Zung self-rating depression scale assesses depressive features rather than diagnosing a specific depressive disorder such as a major depressive disorder, a mood disorder due to HIV disease, or an adjustment disorder with depressive features. Some features on the Zung scale are not exclusively depressive and may be related to HIV/AIDS rather than depression. The Zung scale is a screening instrument and there may have been false-negatives and false-positives. Furthermore, the particular setting may not be representative of other places in the province or the country, but further research would be required to investigate whether this is so.

\section{Conclusions}

This study found that depressive features are common among adult patients receiving HAART for HIV/AIDS, who attend PHC facilities in Rustenburg district. Depressive features occured in $71.8 \%$ of the patients, with $69.2 \%$ having mild depressive features, $1.7 \%$ moderate depressive features and $0.9 \%$ severe depressive features. Being unmarried and taking an HAART regimen containing efavirenz seems to be associated more commonly with depressive features. In HIV/AIDS management, screening for depressive features should be considered an integral part of comprehensive care; since leaving it undiagnosed has detrimental effects including poor adherence to treatment. When task-shifting HAART to clinics, it is imperative that training be made available for primary-care doctors and nurses to detect and manage mental health conditions, including depression.

As stated in the SASH study, ${ }^{[8]}$ given the significant roles that HIV/AIDS and common mental disorders play in shaping the health of many South Africans, there is a need for better understanding of how HIV/AIDS influences the mental health of the infected. In particular, as emphasis on the provision of care and treatment services to HIV-positive individuals increases, these services provide an opportunity to identify and treat common mental illnesses, including depression. Strengthening the links between HIV/AIDS and mental health services should contribute to substantial gains in the improved management of both conditions.

\footnotetext{
References

1. American Psychiatric Association. Diagnostic and Statistical Manual of Mental Disorders DSM-IV TR. Arlington, VA: American Psychiatric Publishing, 2000.

2. Kerr LK, Kerr LD. Screening tools for depression in primary care: The effects of culture, gender, and somatic symptoms on the detection of depression. West J Med 2001;175(5):349-352.
}

3. Myer L, Stein DJ, Grimsrud AT, et al. DSM-IV-defined common mental disorders: Association with HIV testing, HIV-related fears, perceived risk and preventive behaviours among South African adults. S Afr Med J 2009;99(5):396-402.

4. World Health Organization (WHO). Initiative on Depression in Public Health. Geneva: WHO, 2010. 5. Chandra PS, Desai G, Ranjan S. HIV \& psychiatric disorders. Indian J Med Res 2005;121:451-467.

6. Moosa MYH, Jeenah FY. Treating depression in HIV/AIDS. S African Journal of Psychiatry 2007;13(3):86-88.

7. Bhagwanjee A, Parekh A, Paruk Z, Petersen I, Subedar H. Prevalence of minor psychiatric disorders in adult African rural community in South Africa. Psychol Med 1998;28(5):1137-1147.

8. Herman AA, Stein DJ, Seedat S, et al. The South African Stress and Health (SASH) study: 12-month and lifetime prevalence of common mental disorders. S Afr Med J 2009;99(5):339-344.

9. South Africa HIV/AIDS Statistics. Horsham, UK: Avert; 2010. http://www.avert.org/south-africa-hivaids-statistics.htm (accessed 30 May 2013).

10. Gardner B. Bojanala Platinum District Profile Ewisa. Mmabatho: NWP Department of Health, 2013.

11. Bodibe K. HCT Campaign: The Numbers So Far. Cape Town: Health-e, 2011. http://www.health-e.org. za/news/article.php?uid=20033204 (accessed 19 March 2013).

12. Zung WWK. A self-rating depression scale. Arch Gen Psychiatry 1965;12:63-70.

13. President and Fellows of Harvard College. Depression, Sex and Age. Cambridge, MA: Harvard Health Publications, 2007, 1-5.

14. Yousefi F, Mansor M, Juhari R, et al. The relationship between gender, age, depression and academic achievement. Current Research in Psychology 2010;6(1):61-66.

15. Sale S, Gadanya M. Prevalence and factors associated with depression in HIV/AIDS patients aged 15-25 years at Aminu Kano Teaching Hospital, Nigeria. J Child Adolesc Ment Health 2008;20(2):95-92.

16. Agbir TM, Audu MD, Adebowale TO, Goar SG. Depression among medical outpatients with diabetes: A cross-sectional study at Jos University Teaching Hospital, Jos, Nigeria. Ann Afr Med 2010;9(1):5-10 [http://dx.doi.org/10.4103/1596-3519.62617]

17. Henry K. Internal medicine/primary care reminder: What are the standards of care for HIV-positive patients aged 50 years and older? Curr HIV/AIDS Rep 2009;6(3):153-161

18. Vance DE, Moneyham L, Fordham P, Struzick TC. A model of suicidal ideation in adults aging with HIV. J Assoc Nurses AIDS Care, 2008;19(5):375-84.

19. Nolen-Hoeksema, S. Sex Differences in Depression. Stanford, CA: Stanford University Press, 1990.

20. Culbertson FM. Depression and gender. An international review. Am Psychol 1997;52(1):25-31.

21. Klerman GL, Weissman M. Increasing rates of depression. JAMA 1989;261(15):2229-2235.

22. Leifheit-Limson EC, Reid KJ, Kasl SV, et al. The role of social support in health status and depressive symptoms after acute myocardial infarction: Evidence for a stronger relationship among women. Circ Cardiovascu Qual Outcomes 2010;3:143-150. [http://dx.doi.org/10.1161/ CIRCOUTCOMES.109.899815]

23. Lesserman J, Pence BW, Whetten K, et al. Relation of lifetime trauma and depressive symptoms to mortality in HIV. Am J Psychiatry 2007;164(11):1707-1713. [http://dx.doi.org/10.1176/appi. ajp.2007.06111775]

24. LaPierre TA. Marital status and depressive symptoms over time. Family Relations, 2010;58(4):404-416. [http://dx.doi.org/10.1111/j.1741-3729.2009.00562.x]

25. Jang S, Kawachi I, Chang I, et al. Marital status, gender and depression: Analysis of baseline survey of the Korean longitudinal study of ageing (KLoSA). Soc Sci Med 2009;69(11):1608-1615. [http://dx.doi org/10.1016/j.socscimed.2009.09.007]

26. Dyer S, Lombard C, Van der Spuy Z. Psychological distress among men suffering from couple infertility in South Africa: A quantitative assessment. Oxford University Press, July 2009. Hum Reprod 2009;24(11):2821-2826. [http://dx.doi.org/10.1093/humrep/dep278]

27. Chachamovich E, Fleck M, Laidaw K, Power M. Impact of major depression and sub syndromal symptoms on quality of life and attitudes toward aging in an international sample of older adults. Gerontologist 2008;48(5):593-602

28. Kumar V, Encinosa W. Effects of antidepressants treatment on antiretroviral regimen adherence among depressed HIV-infected patients. Psychiatr Q 2009;80(3):131-141. [http://dx.doi.org/10.1007/ s11126-009-9100-z]

29. Horberg MA, Silverberg MJ, Hurley LB, et al. Effects of depression and selective serotonin reuptake inhibitor use on adherence to highly active antiretroviral therapy and on clinical outcomes in HIVinfected patients. J Acquir Immune Defic Syndr 2008;47(3):384-390. [http://dx.doi.org/10.1097/ QAI.0b013e318160d53e]

30. Zulu H. Depression, the Worst Killer in Africa. Calgary: Zulu Publications, 2003.

31. Koller M. Hysteresis and unemployment in South-Africa. http://www.essa.org.za.

32. Kartha D. Mild depression. http://www.buzzle.com/articles/mild-depression.html (accessed 15 March 2013).

33. Barnaard K. Mild depression (letter). http://www.netdoctor.co.uk/ate/depression/202022.html (accessed 30 May 2013).

34. Siddharth SH, Jensen PT, Lahey T. Living in rural New England amplifies the risk of depression in patients with HIV. BMC Infect Dis 2009;9:25. [http://dx.doi.org/10.1186/1471-2334-9-25]

35. Osuji OT. African Immigrants in America. http://nigeriavillagesquare.com/articles/ozodi-thomasosuji/african-immigrants-in-america.html (accessed 30 June 2012).

36. Aidsinfonet.org. Depression and HIV. http://www.aidsinfonet.org/fact_sheets/view/558 (accessed 13 June 2012).

37. Seedat S. Assessment and management of depression in HIV. HIV/AIDS and Mental Health, 2007; 27:2-3.

38. Price J, Butler R, Hatcher S, Von Korff M. Depression in adults: Psychological treatments and care pathways. Clin Evid (online) 2007:1016.

39. Lovegrove B. Practical ideas and suggestions for coping with mild depression. http://ezinearticles. $\mathrm{com} /$ ?Practical-Ideas-and-Suggestions-For-Coping-With-Mild-Depression\&id=3332700 (accessed 30 May 2013). 